\title{
ARTICULACIÓN DEL ACTOR-RED: ANÁLISIS DE LAS MEDIACIONES EN TORNO A LA LEY 975 DE 2005 DE COLOMBIA (LEY DE JUSTICIA Y PAZ)
}

\section{NETWORK JOINT ACTOR ANALYSIS MEDIATIONS AROUND LAW 975 OF 2005 COLOMBIA (LAW OF JUSTICE AND PEACE)}

\author{
Jennifer Del Toro-Granados ${ }^{1}$, Erika Olivo-Rada ${ }^{2}$, Liseth Ardila-Vergara $^{3}$ y Beatriz Pimienta-Anaya ${ }^{4}$
}

\section{RESUMEN}

El presente trabajo pretendió reflexionar a partir de la teoría del actor-red en las mediaciones que hicieron posible y determinaron la proclamación de la ley 975 de 2005 o ley de justicia y paz. Se concluye que existieron diversos actores humanos y no humanos que fueron enrolados con el objetivo de expedir una ley que derivó en un proceso de impunidad y legitimación de la escalada paramilitar en Colombia; además se establece el plano jurídico como un espacio de disputas donde los intereses de los victimarios se enfrentan con los intereses de las víctimas en un juego político que ubica a estos últimos actores en nuevas situaciones de victimización.

Palabras Clave: Ley; justicia transicional; Actor Red.

\section{ABSTRACT}

This work employs actor-network theory to reflect on the mediations that determined who made the proclamation of Law 975 of 2005 (Law of Justice and Peace). There were various human and non-human actors enrolled with the objective of issuing a law that led to a process of impunity and legitimation of paramilitary actions in Colombia. The legal sphere became an arena where the interests of the perpetrators confronted the interests of the victims in a political game that places the latter in new situations in which they are still the victims.

Keywords: law; transitional justice; Actor-Network.

Tipología: Artículo de Investigación Científica y Tecnológica

Fecha de recepción: 25/03/2015

Fecha de aceptación: 28/07/2015

Como citar este artículo: Del Toro-Granados, J., Olivo-Rada, E., Ardila-Vergara, L. \& Pimienta-Anaya, B. (2015). Articulación del actor-red: Análisis de las mediaciones en torno a la ley 975 de 2005 de Colombia (Ley de justicia y paz). Jangwa Pana, 14, 75 - 89.

1. Psicóloga, posgrado en psicología social de la Universidad de Buenos Aires. Becaria Colciencias en modalidad "formación de capital humano de alto nivel para las regiones. Joven investigadora Colciencias, Colombia. Correo: jennydeltoro2@gmail.com

2. Psicóloga, Universidad del Magdalena, Colombia. Correo: Erikaolivorada@hotmail.com

3. Psicóloga, Universidad del Magdalena, Colombia. Correo: lissitardila@gmail.com

4. Psicóloga, Universidad del Magdalena, Colombia. Correo: Beatriz-naya@gmail.com 


\section{INTRODUCCIÓN}

$\mathrm{L}$ a teoría del actor red surge en la década del 80 en Francia como producto de una crítica radical de la sociología contemporánea. De acuerdo con su máximo exponente (Bruno Latour), "lo social" es asumido tradicionalmente como una "caja negra" que no necesitaría ser explicada, generando una especie de estatismo de lo social. Para Latour (1992) el trabajo de la sociología es rastrear, mapear y describir los discursos, dispositivos, escenarios, intereses, etc. que se "enrolan" y hacen posible un resultado. Otro aspecto novedoso de la TAR es incluir en los análisis de las mediaciones a los actores "no humanos" en tanto estos detentan potencial de agencia, es decir, influyen en la construcción de la realidad.

Para la teoría del actor red, los fenómenos de la realidad no deben ser analizados como causas o consecuencias, sino como mediaciones en las que intervienen diversos actantes, es decir, cualquier entidad que genere un efecto de relación (humano o no humano) en palabras de sus autores se considera un actante "Lo que sea que actúa o mueve a la acción” (Akrich \& Latour, 1992).

Por lo tanto, el objetivo del presente trabajo es describir, rastrear y mapear en esas redes que posibilitaron la expedición de la ley 975/2005 o ley de justicia y paz en Colombia. En esta red de actantes se incluyen los análisis de actores humanos y no humanos, así como discursos, territorios, opiniones e intereses.

El trabajo estuvo motivado por los discursos institucionalizados de "desmonte del paramilitarismo" y en la semiótica como escenario de disputa. El término "bandas criminales" se empieza a usar con fuerza en el país posterior a la implementación del proceso de justicia y paz, como una estrategia para sostener el proceso mismo, es un término cargado de sentido (diferente) tanto para víctimas, victimarios y sociedad general.
Las BACRIM (bandas criminales) se entienden como:

organizaciones criminales (macro delincuenciales) significativamente armadas, que desarrollan actividades tanto de control de grandes negocios ilícitos como de depredación subsidiara de los mismos, y que con frecuencia emplean la violencia como mecanismo de disciplinamiento interno, de delimitación de áreas de influencia específicas y de coacción unilateral sobre terceros a fin de mantener las condiciones de operación requeridas por sus actividades. (Oficina del Alto Comisionado para la Paz, Presidencia de la República de Colombia, 2010)

Los sentidos otorgados a estas bandas criminales difieren dependiendo de quién lo utilice; un sector conviene en afirmar que estas bandas son una nueva configuración del conflicto interno armado, con nuevas lógicas de operación y que carecen de un motor de naturaleza política para su accionar; mientras que otro sector sostiene que estas bandas criminales no son otra cosa que el rearme paramilitar, que conserva la misma estructura militar, mismo accionar basado en el saqueo por la modalidad de "tierra arrasada", desplazamiento masivo, desapariciones forzadas, masacres, asesinatos selectivos y captura de lo público como mecanismo de perpetuación del poder.

Es importante, para no caer en el reduccionismo de "lo social", describir y rastrear el fenómeno del que nos ocupamos. A continuación se presenta una descripción (limitada) de los procesos que intervinieron en el surgimiento, expansión y consolidación del fenómeno paramilitar en Colombia. La ley 975/2005 trata de ser "descajanegrizada", es decir, trata de ser abierta y analizada como un dispositivo de enrolamiento de intereses. 
El conflicto interno armado colombiano se considera como uno de los más sangrientos de la historia contemporánea de América Latina. De acuerdo con reportes oficiales entre el periodo comprendido entre 1958-2012, 220.000 personas perdieron la vida por causas relacionadas con el conflicto armado (Centro de memoria histórica).

Si bien es cierto que el conflicto armado en Colombia es multi-causal, también es cierto que en sus diferentes periodos ha presentado una constante y es: el control político, económico, el dominio del aparato estatal y el control de la tierra. Es así como se evidencia que en la violencia partidista de la década del 50, conservadores y liberales libraron una batalla que se prolongó durante 30 años y en la cual perdieron la vida más de 193.000 personas, esta época denominada con el nombre genérico de la "Violencia" se caracterizó por la fuerte represión de los movimientos agrarios y por la degradación de la guerra expresada en actos de sevicia y tortura (Chernick, 2008; Duran, 2008; Gaitan \& Deas, 1995).

Posterior al asesinato del caudillo liberal Jorge Eliecer Gaitán, orquestado por dirigentes conservadores y algunos miembros de la derecha liberal; el fenómeno de la violencia se trasladó rápidamente a todas las regiones del país, los conservadores iniciaron una guerra sucia a través de sus fuerzas militares y a través de ejércitos privados de "chulavitas y pájaros" encargados de asesinar "comunistas". Este es un elemento originario de la estigmatización que se sostiene aún en Colombia hacia los campesinos pobres, los dirigentes de izquierda y los defensores de derechos humanos. Las organizaciones campesinas conformaron retaguardias estratégicas en algunas regiones del centro y sur del país (Gómez, 2001; Holmes, Gutiérrez \& Curtis, 2006; Leal, 2006; Pizarro, 2004).

Los “chulavitas y pájaros" de la década del 50 se configuran entonces como el primer auge paramilitar, desde ese momento se delata su accionar terrorista, que persigue a través de la sevicia, la tortura, las masacres y la desaparición; no solo la aniquilación del adversario, sino, y más importante aún, el sometimiento y control de la población entera; se evidencia además cómo desde sus orígenes el paramilitarismo ha sido un fenómeno asociado a las fuerzas del Estado, dinámica que se sostiene en la actualidad.

A pesar de la fuerte represión dirigida por las fuerzas militares y paramilitares al movimiento guerrillero, este tuvo un fuerte auge en la década del 60 caracterizado por la incursión de la lucha subversiva en áreas urbanas; en ese contexto se inscriben las acciones del movimiento 19 de Mayo (M-19) y la estrategia de combinar todas las formas de lucha. Colombia, entonces no fue ajena al fenómeno de Mayo Francés, la caída de Batista en Cuba y la guerra fría, puesto que estos fenómenos globales insuflaron esperanza a los movimientos subversivos de América Latina, el ejemplo del triunfo de la revolución cubana y el apoyo del bloque socialista en cabeza de la URSS a la guerrilla de Cuba catalizó los procesos revolucionarios en centro y sur América (Sánchez \& Peñaranda, 1991; Díaz, Fernández \& Rodríguez, 2013).

Surgen por esta época también las guerrillas del Ejército de Liberación Nacional (ELN), Ejército Popular de Liberación (EPL). Frente al surgimiento de multitud de grupos armados, el gobierno colombiano, actuando por recomendaciones estadounidenses, ofrece una salida negociada al conflicto, a este proceso se suman varias organizaciones subversivas; sin embargo la guerrillas de las FARC y del ELN, rehúsan hacer parte del proceso de amnistía (Borja, 2008).

Es en este contexto donde se abre la puerta a la privatización de la lucha contrainsurgente a partir del decreto legislativo Número 3398 de 1965, el cual establece en sus consideraciones que "Es perentoria la obligación del Estado velar por el bienestar y la protección de los asociados brin- 
dándoles el clima de confianza que emana del cumplimiento de las medidas de seguridad nacional" y por lo tanto "la movilización y la defensa civil, por su importancia y trascendencia, deben ser ampliamente conocidas por la población colombiana, ya que tales aspectos competen a la nación entera, y no son de incumbencia exclusiva de las fuerzas armadas" y reglamenta en su artículo 24 que "la participación en la defensa civil es permanente y obligatoria para todos los habitantes del país" y en su artículo 25 "Todos los colombianos, hombres y mujeres, no comprendidos en el llamamiento al servicio militar obligatorio, podrán ser utilizados por el gobierno en actividades y trabajos con los cuales contribuyan al restablecimiento de la normalidad" (Restrepo, 2006). Esta norma es expresión de formas singulares de protección de la propiedad privada, que en este caso recae sobre la población civil y que legaliza la operación del paramilitarismo en el país; esta norma es lo que considera la TAR un mediador no humano, que a pesar de no detentar el poder de "intencionalidad" genera un efecto, tiene poder de agenciamiento en el sentido que más allá de la intencionalidad estos actores ( $\sin$ ser causa o consecuencia) median en el entramado del actor-red (Law,1987; Latour, 1998; Latour, 1986).

Es preciso señalar que, a pesar del sentido jurídico del decreto 3398/65, las estructuras paramilitares en Colombia no se establecieron, ni funcionaron como asociaciones de ciudadanos enfrentados al crimen; por el contrario se agruparon como estructuras armadas que ejercieron violencia de tipo conservadora en aras de sostener un orden sociopolítico establecido, esto es, escapa de la visión exclusiva de combate contrainsurgente; más adelante se analizará la relación entre el proyecto "autodefensas unidas de Colombia" y la expansión de mega proyectos de tipo minero y agrícola en el país.

Como mediación de la ley, en la década de los 70 un grupo de ganaderos, terratenientes y esmeralderos se reúnen en un sector del centro del país (Puerto Boyacá) con el objetivo de unir esfuerzos junto con las fuerzas militares y los nacientes carteles del narcotráfico para la consolidación de un grupo armado que fuera capaz de proteger su capital privado del accionar guerrillero (Rettberg, 2010).

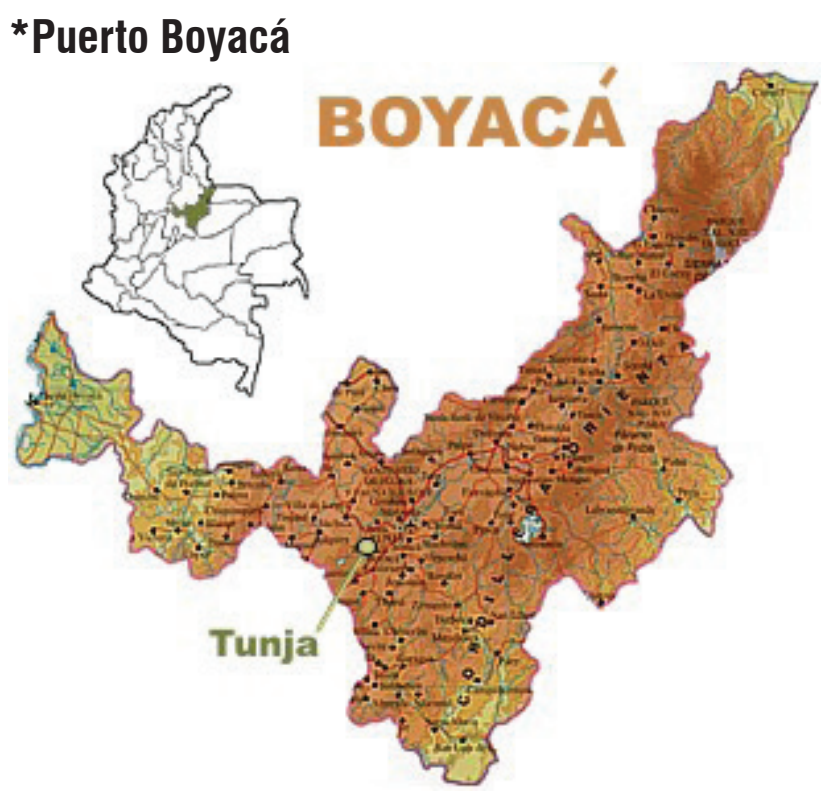

Figura 1. Territorio de configuración de las Autodefensas Unidas de Colombia. Fuente: Google maps

Geográficamente, Puerto Boyacá (Figura 1) es un municipio situado en las coordenadas $5^{\circ} 58^{\prime} 34^{\prime \prime} \mathrm{N}, 74^{\circ} 35^{\prime} 15^{\prime \prime} \mathrm{W}$ en el Departamento de Boyacá, centro de Colombia. Es un importante centro comercial que conecta a través del río Magdalena a todo el país y que se encuentra estratégicamente situado cerca a los principales centros urbanos (Medellín, Bogotá, Cali y Bucaramanga). Hace parte además del cinturón esmeraldifero de Colombia, una extensión territorial de $250 \mathrm{~km}$ de largo por $50 \mathrm{~km}$ de donde se extraen las esmeraldas más puras del mundo.

En Puerto Boyacá además, se instauró en la década del 80 el primer centro de entrenamiento profesional de paramilitares a cargo del mercenario Israelí Yaìr Klein; quien se desplazó a Colombia de acuerdo con sus declaraciones "contratado por esmeralderos, ganaderos y terratenientes asediados por la guerrilla". Yaìr Klein fue contactado 
por el oficial del ejército Luis Meneses, quien logró enrolar los intereses de esmeralderos, ganaderos, empresas de seguridad privada, la contratista israelí Hat-AL, traficantes de armas, fuerzas militares y dirigentes políticos (Velásquez, 2007), en una red amplia con intereses en la conservación de un orden sociopolítico determinado. De acuerdo con la teoría del actor red el concepto de enrolamiento se refiere a "Proceso por el cual los actantes hacen formar parte de su red a otros actantes. La estabilización temporal de ciertos procesos de enrolamiento son los denominados intereses sociales y también da lugar a las relaciones de poder. Los procesos de enrolamiento son los procesos mediante los cuales unos actores pretenden imponer a otros una determinada visión del mundo social o natural" (Latour, 2005); desde esta teoría se propone que la acción de los diferentes actantes no se constituye ni en causa ni en efecto, sino que se comporta como mediación, esta visión nos permite entender el accionar de los actores, no como "causantes, determinantes, originadores" de los fenómenos, sino como elementos con potencial de acción que se unen para constituir una red. Es interesante analizar la expansión paramilitar en clave territorial, debido a la estrecha relación que presenta esa expansión con la riqueza de los territorios; es decir, en Colombia, la guerra interna se ha desarrollado con mayor intensidad y ha tenido mayor auge en las zonas con mayor riqueza natural, y se ha configurado como un conflicto rural, de tal manera que los efectos del terror en términos de "opinión pública" han sido generalmente invisibilizados (esta invisibilidad que no ha sido para nada ingenua, permite por un lado esconder el padecimiento de las víctimas, por otro evitar la mirada de la comunidad internacional sobre la violación sistemática de derechos humanos en Colombia y finalmente evitar que los Colombianos ignoren la precariedad de la democracia).

Fue a partir de la década del 80, cuando el paramilitarismo logra constituirse como proyecto político, militar y económico que se extiende por medio de prácticas terroristas a través de todo el territorio, Inicialmente operaron del centro hacia el norte, donde consiguieron un amplio respaldo de sectores económicos de elite, constituyendo la Costa Caribe como su bastión político-militar; y luego de centro hacia el Sur, donde se libraron cruentos enfrentamientos con las guerrillas que tenían su afianzamiento en el sur del país (Sánchez \& Chacón, 2006); la aplicación de la doctrina de enemigo interno logró estigmatizar al total de la población y eliminar las fronteras entre combatientes y población civil (Uprimmy, 2001; Vargas, 2009).

Otra estrategia para la consolidación el proyecto paramilitar en Colombia fue reforzar el terror en las comunidades a través de la exposición pública de actos de crueldad excesiva. Esta dinámica se perpetuó e instauró una nueva geografía del terror caracterizada por pueblos abandonados, cinturones de miseria en los centros urbanos conformados por personas desplazadas y la internalización colectiva del miedo (Centro nacional de memoria histórica, 2013).

En el año 1996, los comandos paramilitares se aglutinan en torno a la organización denominada: Autodefensas Unidas de Colombia (AUC), con estructura militar de comandos, que entrañaba un proyecto político, militar y social; en alianza con las fuerzas armadas y las elites económicas se agrupan bajo el principio de "refundar la patria" es este el periodo de mayor expansión del paramilitarismo en el país, dicha expansión se tradujo en la captura de lo "público" por parte del paramilitarismo. Para el año 2006, cerca de la mitad de los congresistas del país estaban siendo investigados por alianzas con paramilitares; entre los años 2000 y 2008 se suscribieron en el país, una serie de pactos (Ralito, Chivolo, Pivijay, Urabá) en el que políticos de todos los niveles se adherían al proyecto paramilitar a cambio de apoyo por parte de esta organización en el proceso electoral; fue un periodo donde se dejó al descubierto que en territorios capturados a sangre y fuego por el paramilitarismo se presentaban picos electorales en poblaciones históricamente abstencionis- 
tas; el proyecto de refundación, bandera de las autodefensas, logró en todo el país no solo elegir cargos de elección popular, sino capturar las funciones de gobierno y estado que tendrían los candidatos que resultaran elegidos (Gutiérrez, 2004; Arias, 2008).

Para el año 2002, el proyecto paramilitar se encontraba consolidado, por un lado las elites económicas vieron en este proyecto la oportunidad de expandir sus capitales a través de la "compra" de tierras usurpadas a los campesinos y vincularse al lucrativo negocio de los megaproyectos de agrocombustibles y minería a gran escala; los políticos (que generalmente hacen parte de estas mismas elites económicas y operan en zonas como la costa atlántica como verdaderos cacicazgos) lograron a través de la coerción hacerse elegir (Romero, 2007) (garantizando el control de los recursos producto de las transferencias nacionales y las regalías en determinados Departamentos como Cesar y Magdalena), subordinando las Instituciones públicas y de representación a intereses ilegales. Al tiempo que uno de los principales comandantes de las AUC declaraba públicamente que su organización había superado la meta de elegir el 35\% del congreso, se alistaba el marco jurídico que les permitiera negociar la “desmovilización” (Valencia, 2007).

El marco jurídico que reguló la desmovilización y reinserción de paramilitares estuvo rodeado de múltiples controversias. El 22 de Enero 2003 el entonces presidente de la República, Álvaro Uribe Vélez, firma el decreto número 128/2003 (por el cual se expiden normas sobre concesión de beneficios a quienes abandonen voluntariamente las organizaciones subversivas). En este, se establecen las condiciones para el otorgamiento de beneficios socioeconómicos y jurídicos a los combatientes no condenados por crímenes de lesa humanidad; los beneficios incluyeron exoneración de responsabilidad penal (indulto, cesación de procedimiento, resolución inhibitoria y suspensión condicional de la pena).
El decreto en mención fue aprobado un mes después de haberse expedido la ley 782 de 2002 (diciembre), aunque en apariencia son legislaciones similares en tanto su objeto es regular el proceso de desmovilización y reinserción de los paramilitares; sustancialmente entraña diferencias abismales, mientras que en el texto de la ley $782 / 2002$ se menciona que los paramilitares que "hayan cometido" crímenes de lesa humanidad no podrán ser beneficiarios de la ley; en el texto del decreto 128/2003 la expresión "hayan cometido" es sustituida por la expresión "hayan sido juzgados y condenados" de esta manera se individualiza a responsables de crímenes atroces y se desliga al sistema penal de la administración de justicia por vía probatoria, en últimas se restringe el derecho de las víctimas y del colectivo en general a la verdad (López, 1999; González, 2005; Pearl, 2010; Pérez, 2005).

Múltiples organizaciones de derechos humanos han demandado el decreto por considerar que es inconstitucional e invisibiliza el drama de las victimas, así como la posibilidad de conocer el paramilitarismo en contexto y su vinculación con una estrategia sistemática de violación de derechos humanos amparada en instituciones del estado y apoyada por elites económicas y políticas nacionales e internacionales (Gallón \& Díaz, 2004; Human Rights Watch; 2005; Naciones Unidas, 2004). Sin embargo, en el marco de ese decreto considerado una amnistía de facto, se desmovilizaron $31.454(92,7 \%)$ paramilitares sin estar obligados jurídicamente a revelar la verdad sobre los crímenes cometidos, fuentes de financiación y cómplices estatales, constituyéndose el evento en una violación al derecho de las víctimas a la verdad la justicia y la reparación; además de favorecer la conservación de sus estructuras criminales.

A pesar de que casi la totalidad de los miembros del paramilitarismo pudieron legalizarse a partir del marco jurídico creado en torno a la ley $782 / 2002$ y al decreto $128 / 2003$, aún faltaba ne- 
gociar la desmovilización de aquellos paramilitares acusados o condenados por crímenes de lesa humanidad y crímenes de guerra que no pudieron acogerse a las leyes antes mencionadas. Es en este contexto donde se aprueba por parte del congreso el 22 de junio de 2005 la ley de justicia y paz presentada por el gobierno.

El objeto de la ley 975 establece que "La presente ley tiene por objeto facilitar los procesos de paz y la reincorporación individual o colectiva a la vida civil de miembros de grupos armados al margen de la ley, garantizando los derechos de las víctimas a la verdad, la justicia y la reparación" (Oficina del alto comisionado para la paz, 2010). Es claro en este punto que la ley 975 es una norma de carácter residual en tanto se crea para legalizar la situación de los paramilitares que cometieron delitos de lesa humanidad, y por lo tanto, no pudieron acogerse al anterior marco normativo. Durante la discusión de la ley en el Congreso, el gobierno, en cabeza del entonces viceministro de justicia Mario Iguarán (posteriormente elegido entre una terna como Fiscal general de la nación, entidad encargada de vigilar el cumplimiento de la ley de justicia y paz) aseguraba que esta ley era la única salida posible para el conflicto armado, el desmantelamiento de las estructuras paramilitares y el acceso por parte de las víctimas a los derechos de verdad, justicia y reparación.

\section{Aspectos estructurales de la ley 975}

1. Enfoque de justicia transicional: implica que los perpetradores de crímenes sean sometidos a acciones judiciales a través de tribunales nacionales o internacionales; garantía de la reconstrucción de la memoria histórica (promoción de medidas que favorezcan la búsqueda de la verdad) y la reparación integral de las víctimas de crímenes de lesa humanidad

2. Sistema de alternatividad penal: el principio de alternatividad se plantea como la opción de ofrecer penas alternativas a las establecidas por la justicia ordinaria para los miembros de gru- pos armados acogidos a la ley 975. Las penas privativas de la libertad para los paramilitares desmovilizados se pactaron entre 5-8 años

3. Ley basada en el otorgamiento de incentivos a los victimarios a cambio de contar la verdad y contribuir a la paz nacional. Por lo tanto, es una ley que se aleja del sistema procesal en tanto deja de lado el principio de averiguación procesal y producción de pruebas que permitan poner a prueba el principio de presunción de inocencia. En este marco, los "postulados a justicia y paz" tuvieron la oportunidad de concurrir a los escenarios de "versiones libres" donde brindaron sus "propias" versiones de tiempo, modo y lugar de ocurrencia de sus crímenes. Estas audiencias de versiones libres basada en el individuo y no en el contexto de comisión del hecho punible, excluyó la posibilidad de conocer las dimensiones del fenómeno paramilitar; las versiones individuales fueron una manera de ocultar el patrón sistemático de las violaciones de derechos humanos y, en últimas, de ocultar la alianza histórica entre el estado y sus fuerzas militares con las elites económicas y políticas del país

4. Promoción de un modelo eficientista de justicia: en tanto que la ley fue creada para lograr un "desmonte" rápido y eficiente de las estructuras paramilitares; el objetivo de la ley es producir fallos y descongestionar el sistema de justicia, por lo tanto se facilita que el "postulado a justicia y paz" confiese y acepte los crímenes de lesa humanidad en que incurrió con objeto de su vinculación al paramilitarismo a fin de acogerse a la alternatividad penal. Sin embargo, esta medida deja al descubierto la ineficacia del sistema de producir evidencias y contrarrestar las versiones de los imputados

\section{Aspectos funcionales de la ley 975}

1. Desmovilización: proceso a cargo de la Oficina del Alto Comisionado para la Paz, programa de atención humanitaria al desmovilizado

2. Postulación de los desmovilizados: luego de que el combatiente decide unilateralmente 
desmovilizarse, el gobierno nacional procede a postular ante la fiscalía general de la nación a los desmovilizados, de tal manera que se puedan verificar si el sujeto puede ser amparado con la ley de justicia y paz (Art 10 y 11 de la ley 975)

3. Etapa de justicia y paz: en esta etapa los postulados concurren ante una unidad de justicia y paz a rendir versión libre acerca de los crímenes cometidos con motivo de su pertenencia al grupo armado ilegal, posteriormente concurren a una audiencia de formulación, imputación y aceptación de cargos.

4. Etapa de imposición de la pena alternativa (máximo 8 años) sin importar la magnitud o grado de responsabilidad en la comisión de los crímenes

¿Quiénes aprobaron la ley de justicia y paz?

En el año 2006 se empiezan a hacer públicas en Colombia las relaciones entre políticos de todos los niveles y el paramilitarismo. La alianza que ya era conocida en diferentes sectores del país, empieza a dejar al descubierto de qué manera los políticos se beneficiaron de las acciones armadas y el potencial de intimidación que tenían las AUC sobre la población civil. Los paramilitares aseguraban un caudal electoral para sus candidatos y posteriormente los políticos del paramilitarismo desviaban recursos del erario público (sector salud y regalías) a las arcas de los paramilitares, así mismo filtraban información que beneficiara el accionar paramilitar (desplazamiento, masacres y desapariciones) con el objetivo de consolidar su poder en todo el territorio. La alianza se conoció en los medios de comunicación como "el escándalo de la parapolítica" y puso en evidencia la situación de ilegalidad e ilegitimidad de instituciones como el Congreso de la República.

El periodo por el cual son elegidos los congresistas en Colombia es de 4 años, los congresistas elegidos para el cuatrienio 2002-2006 fueron los encargados de sancionar la ley 975/2005. Posteriormente se conoció que varios de los con- gresistas que aprobaron la ley, se encontraban vinculados a los grupos de extrema derecha.

La tabla 1 permite evidenciar que para el periodo 2002-2006 el Congreso de la República de Colombia estaba constituido por "amigos" del paramilitarismo. De hecho, solo para el año 2008 cobraron sentido las palabras del jefe paramilitar en el sentido de que "los amigos del paramilitarismo" habían alcanzado superar el $34 \%$ de representación. El fenómeno paramilitar en sus reales dimensiones llegó a permear Universidades, entes territoriales, y demás instituciones del estado.

En un extenso análisis jurídico realizado por la Comisión Colombiana de Juristas y el colectivo de abogados José Alvear Restrepo se ponen al descubierto los vacíos procesales de la ley 975; concluyen las organizaciones defensoras de derechos humanos que la mencionada ley se aleja del sistema penal y se constituye en un trámite administrativo o pseudojudicial, en tanto escapa de ella los principios del sistema penal (Colombia libre, 2007; Cubides, 2006; Departamento Nacional de Planeación, 2010).

De acuerdo con (Latour, 1992) escapar de las grandes categorías para explicar lo "social" supone la necesidad de volver al análisis de las conexiones entre los distintos actantes; la TAR al establecer el principio de simetría permite entender (aunque no se restringe a esto) el poder de acción de diferentes actores. Esta acción es vista no como una propiedad exclusiva de actores humanos, que supone causalidad en los fenómenos; sino como "el ejercicio de estar entre; es mediación" de aquí se desprende la noción de que cualquier actor capaz de generar efectos es un mediador y no un intermediario.

¿La ley 975/2005 puede ser considerada entonces un mediador? Si retomamos la definición de mediación utilizada por Latour (2005) en la que esta se considera "como algo que sucede pero no es plenamente causa ni plenamente consecuencia, algo que ocurre sin ser del todo un medio 
ni del todo un fin", podríamos decir que efectivamente la ley 975 se comporta como un verdadero mediador en tanto produce efectos en otros actantes y por supuesto en otras redes.

La ley, como se vio en su contexto de aparición, no fue un punto de partida para el proceso de desmovilización, en tanto surge como una ley subsidiaria, pero tampoco es un punto de llegada a partir del cual se pueda asegurar el desmonte del paramilitarismo, pues como indican los informes de INDEPAZ, la Oficina del Alto Comisionado de las Naciones Unidas para los Derechos Humanos, la misión de acompañamiento al proceso de paz en Colombia de los Estados Americanos, la Corte Penal Internacional (CPI), y decenas de organismos defensores de derechos humanos, las estructuras paramilitares se mantienen intactas tanto en su poderío militar como en sus redes políticas, financieras e industriales y "siguen cometiendo crímenes de lesa humanidad de manera sistemática y generalizada en contra de la población civil"; solo que ahora su nombre, institucionalmente reconocido es "bandas criminales" (Colectivo de abogados Jose Alvear Restrepo, 2007).

Tabla 1. Relación de los congresistas que aprobaron la ley de justicia y paz con los paramilitares

\begin{tabular}{|c|c|c|c|}
\hline NOMBRE & DEPARTAMETO & $\begin{array}{l}\text { PARTIDO } \\
\text { POLÍTICO }\end{array}$ & Vinculación a la parapolítica \\
\hline $\begin{array}{l}\text { Jairo Enrique Merlano } \\
\text { Fernández }\end{array}$ & Sucre & Cambio radical & CONDENADO POR PARAPOLIITICA \\
\hline Habib Merheg Marún & Atlántico & Colombia viva & CONDENADO POR PARAPOLÍTICA \\
\hline Luis Alberto Gil Castillo & Santander & $\begin{array}{c}\text { Convergencia } \\
\text { ciudadana }\end{array}$ & CONDENADO POR PARAPOLIITICA \\
\hline Luis Alfredo Ramos Botero & Antioquia & Equipo Colombia & CONDENADO POR PARAPOLIITICA \\
\hline Dilian Francisca Toro & Valle & Liberal & CONDENADO POR PARAPOLÍTICA \\
\hline Dieb Nicolás Maloof Cuse & Atlántico & MIPOL & CONDENADO POR PARAPOLIITICA \\
\hline Vicente Blel Saad & Bolívar & $\begin{array}{l}\text { Movimiento } \\
\text { de Integración } \\
\text { Popular }\end{array}$ & CONDENADO POR PARAPOLIITICA \\
\hline Luis Eduardo Vives & Magdalena & $\begin{array}{c}\text { Movimiento } \\
\text { de Integración } \\
\text { Popular }\end{array}$ & CONDENADO POR PARAPOLÍTICA \\
\hline Alvaro Alfonso García Romero & Sucre & $\begin{array}{c}\text { Movimiento } \\
\text { Nacional } \\
\text { Progresista }\end{array}$ & CONDENADO POR PARAPOLÍTICA \\
\hline Miguel Alfonso de la Espriella & Bolívar & $\begin{array}{l}\text { Movimiento popu- } \\
\text { lar unido }\end{array}$ & CONDENADO POR PARAPOLIITICA \\
\hline Juan Carlos Martínez & Cauca & $\begin{array}{l}\text { Movimiento } \\
\text { Popular Unido de } \\
\text { Colombia-Liberal }\end{array}$ & CONDENADO POR PARAPOLIITICA \\
\hline Mario de Jesús Uribe Escobar & Antioquia & $\begin{array}{l}\text { Movimiento } \\
\text { Renovación } \\
\text { Acción } \\
\text { Laboral-Liberal }\end{array}$ & CONDENADO POR PARAPOLÍTICA \\
\hline
\end{tabular}




\begin{tabular}{|l|c|c|c|}
\hline \multicolumn{1}{|c|}{ NOMBRE } & DEPARTAMETO & $\begin{array}{c}\text { PARTIDO } \\
\text { POLÍTICO }\end{array}$ & Vinculación a la parapolítica \\
\hline Álvaro Araújo Castro & Cesar & Partido Liberal & CONDENADO POR PARAPOLÍTICA \\
\hline $\begin{array}{l}\text { Salomón de Jesús Saade } \\
\text { Abdala }\end{array}$ & Magdalena & Partido Liberal & CONDENADO POR PARAPOLÍTICA \\
\hline Piedad del Socorro Zuccardi & Sucre & Partido liberal & CONDENADO POR PARAPOLÍTICA \\
\hline Mauricio Pimiento Barrera & Santander & Sí Colombia & CONDENADO POR PARAPOLÍTICA \\
\hline Javier Cáceres Leal & Bolívar & $\begin{array}{c}\text { Sin corrupción } \\
\text { Colombia }\end{array}$ & CONDENADO POR PARAPOLÍTICA \\
\hline Francisco Rojas Birry & Chocó & $\begin{array}{c}\text { Visión Étnica- } \\
\text { Huella Ciudadana }\end{array}$ & CONDENADO POR PARAPOLÍTICA \\
\hline
\end{tabular}

Fuente: Elaboración propia.

El marco jurídico que precede a la ley 975 permitió que más del $90 \%$ de los paramilitares fueran legalizados sin necesidad de contar la verdad histórica acerca de este fenómeno en el país, los paramilitares acogidos a la ley de justicia y paz, se enfrentaron a un proceso en el que pudieron contar la "verdad" sin enfrentarse al principio de contradicción (característico de los sistemas penales), y lograron a partir de las jornadas de versión libre justificar su accionar amparados en la excusa de lucha contrainsurgente (Pombo, 2010).

La ley 975 fue además una manera del estado evadir la actuación de la Corte Penal Internacional y de la Corte Interamericana de Derechos Humanos, en tanto estas solo tienen competencia en los casos que el estado muestre negligencia para sancionar crímenes contra la humanidad. El hecho de imponer sanciones y suscribir el acuerdo de negociación, el estado bloquea la intervención de la CPI.

No obstante, a pesar de que ha transcurrido casi una década de entrada en vigencia de la ley $975 / 2005$, hasta el momento solo se han proferido 14 sentencias y han sido condenados 12 paramilitares. En ninguna de las sentencias proferidas se ha llegado a establecer la identidad de los altos responsables (Roy, 2005).
El proceso de justicia y paz ha estado caracterizado por la fragmentación, lo cual facilita que aspectos como la reparación de víctimas se denote como un tema económico y simbólico, sin posibilidad de establecer el verdadero alcance de las alianzas entre grupos armados e institucionalidad, lo cual favorece la conservación de estructuras delincuenciales y dificulta el cumplimiento de los pilares de un proceso de justicia transicional (verdad, justicia, reparación y garantías de no repetición).

\section{DISCUSIÓN}

La teoría del actor red es una propuesta novedosa para el abordaje y comprensión de fenómenos complejos. La posibilidad de incluir nuevos actores y eliminar las dicotomías entre humano/ no humano, subjetividad/objetividad permiten además ampliar las lentes y escapar de visiones reduccionistas que plagan el saber producido en ciencias sociales.

Ante la pregunta básica de ¿qué es lo social? La TAR es radical y establece que, en realidad, bajo este "paraguas" de lo social se pretende agrupar tanto preguntas como respuestas, impidiendo el análisis de las asociaciones que explican la existencia de ciertos fenómenos y develar que 
aquello denominado "social" con todo su manto misterioso, determinista y lejano, es en realidad susceptible de ser estudiado a partir de las asociaciones que genera.

Aunque la TAR, es una teoría de origen europeo que recientemente cobra importancia en los centros de producción de conocimiento de Latinoamérica, es necesario considerar los aportes que empieza a brindar en campos tan diversos como comportamiento vial, educación, carrera armamentista y también campo jurídico o conflicto interno armado.

En el conflicto armado interno colombiano se han conjugado toda clase de situaciones extremas que degradan la dignidad humana. Un conflicto que en medio siglo de vigencia ha dejado, de acuerdo con datos del centro de memoria histórica, 220 mil muertos, 25 mil desaparecidos, 5,7 millones de desplazados, 27 mil secuestrados y más de 2 mil masacres (Centro Nacional de Memoria Histórica, 2008).

El estado colombiano ha ensayado alternativas para restablecer la paz, se han logrado desmovilizaciones de varios grupos insurgentes; no obstante, los fenómenos estructurales que sostienen el conflicto en el país (tenencia y distribución de la tierra, rezago, exclusión y pobreza) no se han transformado (Restrepo, 2006). A pesar de esto, en el año 2005 con la promulgación de la ley 975/2005 (justicia y paz), se empiezan a introducir en el país las nociones de "justicia transicional" discusiones que abarcan el tema de las víctimas y la necesidad de reparación integral; el marco de atención a víctimas del conflicto armado interno (CAI) colombiano se amplía en el 2012 con la entrada en vigencia de la ley 1448/2011 (ley de víctimas) (Pearl, 2010; López, 1999).

Los procesos de justicia transicional en el mundo han enseñado que la reparación es un proceso integral que trasciende los aspectos jurídicos, procedimentales y burocráticos, donde la indemnización económica es apenas un elemento del proceso.

Al respecto cabría preguntarse si en un país como Colombia, donde no existe un eje central a partir del cual explicar el conflicto, y por el contrario es en la sumatoria y superposiciones de las particularidades donde se encuentran escenarios, actores, contextos, dispositivos y mediadores que permiten entender el conflicto generalizado al que se asiste en la actualidad, las dinámicas propias de las regiones construidas al margen (en lo periférico) del proyecto de nación influyen en la interpretación y percepción de las víctimas con respecto al conflicto mismo, sobre todo si se parte de que las relaciones entre la región periférica y el estado han sido históricamente de deslegitimación mutua.

En el contexto actual del conflicto armado, marcado por los diálogos de paz con la guerrilla de las FARC, y el supuesto desmantelamiento de las estructuras paramilitares, implica ahondar en el diálogo académico acerca de los retos que supone la transición a un escenario de paz. Es necesario intensificar la investigación en temas de análisis histórico y contextual del conflicto armado en Colombia, de tal manera que se puedan sistematizar los aprendizajes y proponer alternativas de construcción de un estado-nación inclusivo en el que la paz sea entendida en su verdadera dimensión, es decir, más allá de la dejación de las armas por parte de los actores armados ilegales. 


\section{La parapolítica en clave territorial}

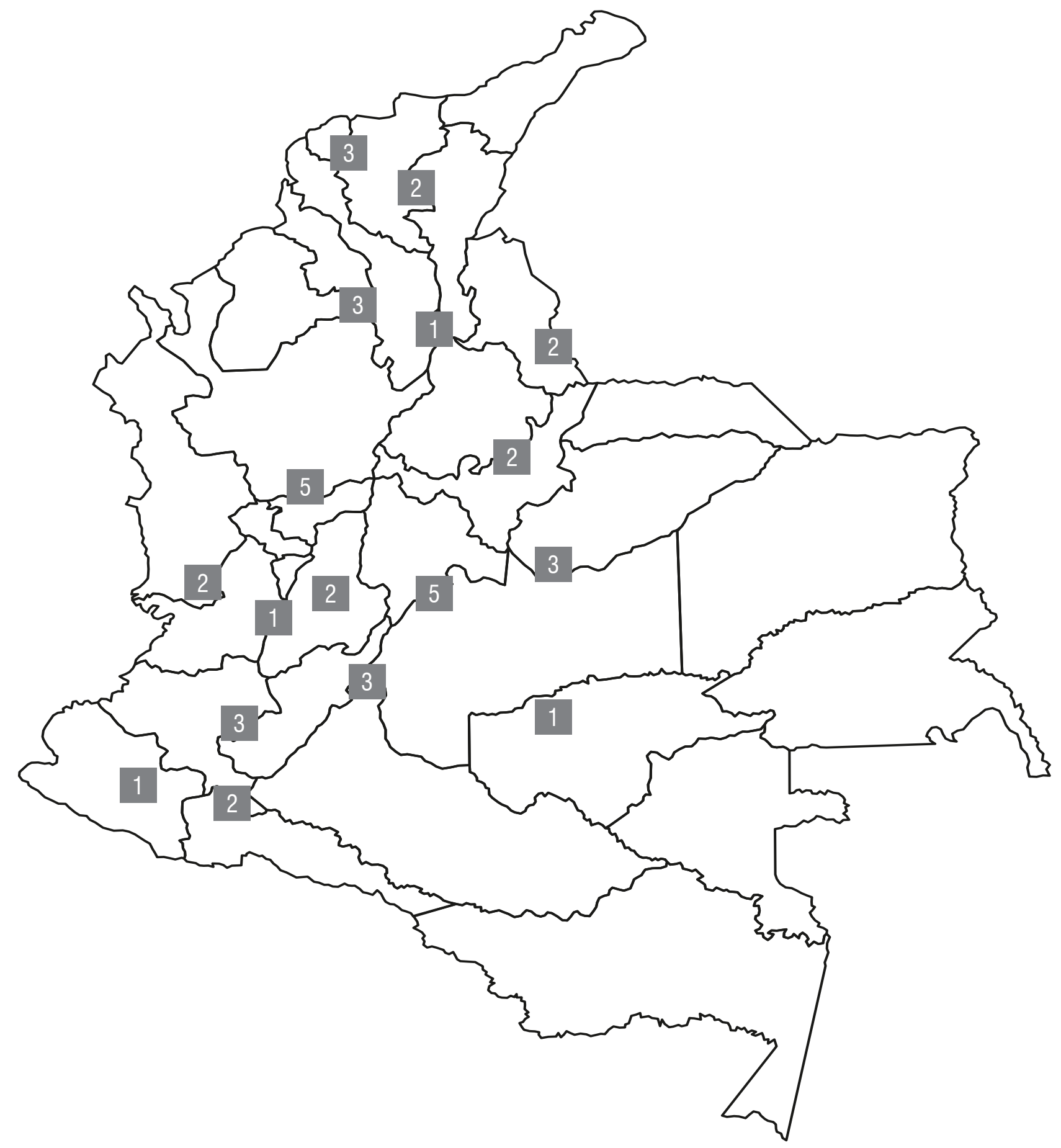

Figura 2. La parapolítica en clave territorial: congresistas aliados a los paramilitares distribuidos por Departamento. (Los números ubicados en los recuadros rojos hacen referencia al número de congresistas por departamento vinculados con el paramilitarismo) Fuente: Elaboración propia. 


\section{REFERENCIAS BIBLIOGRÁFICAS}

Akrich, M. \& Latour, B. (1992). A Summary of a Convenient Vocabulary for the Semiotics of Human and Nonhuman Assemblies. Recuperado de http:/www.conceptlab.com/notes/akrichlatour-1992-convenient-vocabulary.html.

Arias, I. (2008). "Una mirada atrás: procesos de paz y dispositivos de negociación del gobierno colombiano". Recuperado de http://www. ideaspaz.org/secciones/publicaciones/download papers fip/mirada atras web.pdf

Borja, M. (2008). La Subversión en Colombia: El Cambio Social En La Historia. Análisis Político, 21(64), 130-133.

Centro Nacional de Memoria Histórica. (2008). Una guerra prolongada y degradada. Dimensiones y modalidades de la violencia. Recuperado de: htpp:// http://www. centrodememoriahistorica.gov.co/descargas/ informes 2013/bastaYa/capitulos/basta-yacap1_30-109.pdf.

Chernick, M.W. (2008). Acuerdo posible: solución negociada al conflicto armado colombiano. Bogotá: Ediciones Aurora.

Colectivo de abogados José Alvear Restrepo. (2010). Balance del proceso de desmovilización de los paramilitares en Colombia. Recuperado de http://www.colectivodeabogados.org/article. php3?id_article $=1070$

Colombia. (Ene. 25 1966) Ministerio de defensa Nacional. Decreto legislativo 3398 DE 1965 por el cual se organiza la defensa nacional. Diario Oficial, 31.842.

Colombia. (Ene. 24 2003) Ministerio del interior. DECRETO 128 DE 2003 por el cual se reglamenta la Ley 418 de 1997, prorrogada y modificada por la Ley 548 de 1999 y la Ley 782 de 2002 en materia de reincorporación a la sociedad civil. Diario oficial, 45073.

Colombia. (Dic. 23 2002) Congreso de Colombia. Ley 782 de 2002 por medio de la cual se prorroga la vigencia de la Ley 418 de 1997, prorrogada y modificada por la Ley 548 de 1999 y se modifican algunas de sus disposiciones. Diario oficial, 45043.
Colombia. (Jul. 25 2005) Congreso de la república. Ley 975 de 2005 por la cual se dictan disposiciones para la reincorporación de miembros de grupos armados organizados al margen de la ley, que contribuyan de manera efectiva a la consecución de la paz nacional y se dictan otras disposiciones para acuerdos humanitarios. Diario oficial, 45.980.

Colombia. (Jun. 10 de 2011) Congreso de Colombia. Ley 1448 de 2011 por la cual se dictan medidas de atención, asistencia y reparación integral a las víctimas del conflicto armado interno y se dictan otras disposiciones. Diario oficial 48096.

Colombia libre. (2007). "La Ley de Justicia y Paz avanza a "marchas forzadas", El Nuevo Siglo. Recuperado de http://www.colombialibre.org/ detalle_col.php?banner $=6 \& i d=17173$. Cubides, F. (2006). "Proceso inconcluso, verdades a medias: para un balance de las negociaciones del gobierno Uribe con los paramilitares". Revista Análisis Político, (57), 55-64.

Díaz, C., Fernández, C. \& Rodríguez, J. (2013). Doce miradas del conflicto Colombiano. Instituto de estudios Internacionales y Europeos Francisco de Vitoria. Recuperado de http://perso.unifr.ch/derechopenal/assets/files/obrasportales/op_20130808_01.pdf

Departamento nacional de planeación. (2010). Borrador documento CONPES "Política Pública de Atención y Reparación a Víctimas de la Violencia Armada", Bogotá. DNP

Duran, M. (2008). El conflicto armado Colombiano: ¿El fin del fin? CINEP. Recuperado de http://www.alboan.org/docs/articulos/canales/alboan/InformeCINEPsitu.pdf. Gaitán, F. \& Deas, M. (1995). Dos ensayos especulativos sobre la violencia en Colombia. Bogotá: FONADE-DNP

Gallón, G. \& Díaz, C. (2004). "Ni verdad, ni reparación, ni paz: negociaciones para la impunidad de los paramilitares en Colombia". Comisión Colombiana de Juristas. Recuperado de http://www.coljuristas.org/documentos/ documentos_pag/barcelona. pdf, recuperado: Noviembre de 2013 
Gómez, H. (2001). El lío de Colombia. ¿Por qué no logramos salir de la crisis?, Bogotá, Tercer Mundo Editores

González, J. (2005). "Verdad, justicia y reparación en la mitología penal. A propósito de la Ley 975 de 2005". Revista Estudios Políticos, (27), 45-63.

Gutiérrez, F. (2004). Criminal rebels? A discussion of civil war and criminality from the Colombian experience. Politics \& Society 32(4), 257-285.

Holmes, J., Gutiérrez, P. \& Curtin, K. (2006). Drugs, violence, and development in Colombia: A department-level analysis. Latin American. Politics \& Society, 48(3), 157-184.

Human Rights Watch (2005). ColombiaMecanismos de desmovilización garantizan la injusticia, recuperado de http:/www.hrw.org/ legacy/spanish/press/2005/colombia_paras_ desmovilizacion.html

Latour, B. (2005) Reassembling the Social. An Introducition to Actor-Network Theory. Oxford: Oxford University Press.

Latour, B. (1992) Ciencia en acción. Barcelona: Labor.

Latour, B. \& Hermam, E.(1998): Paris ville invisible, Paris, La Decouverte-Les Empecheurs de penser en rond.

Law, J. (1987) Technology and heterogeneous engineering: the case of the Portuguese expansion. Social Construction of Technical Systems: new directions in the sociology and history of technology. Cambridge: MIT Press.

Leal, F. (2006). Políticas de seguridad: de improvisación en improvisación. En la encrucijada, Colombia en el Siglo XXI. Bogotá: Grupo Editorial Norma.

López, W. (1999). "Las políticas de la paz y los procesos de negociación en Colombia. Breve balance y perspectivas". Recuperado de: http://redalyc.uaemex.mx/redalyc/pdf/105/10501911. pdf

Naciones Unidas (2004). "Para lograr la paz en Colombia se necesitan justicia, verdad y re- paración". Recuperado de: http://www.hchr. org.co/ publico/pronunciamientos/ponencias/ po0436.pdf.

Oficina del Alto Comisionado para la Paz, Presidencia de la República de Colombia (2010). Ley de Justicia y Paz. Avances en el Proceso de Justicia y Paz. Recuperado de http:// www.cej.org.co/index.php/todos-justi/2402avance-de-los-procesos-de-justicia-y-paz

Pearl, F. (2010). Prólogo. Buscando un equilibrio entre la justicia y la paz: Avances y perspectivas de la Ley 975 de 2005, Bogotá: Fundación Konrad Adenauer.

Pérez, W. (2005). “Orden jurídico, negociación, paz y reinserción: la constante imbricación entre guerra, política y derecho en Colombia”. Estudios Políticos, No. 27, Instituto de Estudios Políticos, Universidad de Antioquia, pp. 67-100.

Pizarro, E. (2004). Una democracia asediada: Balance y perspectivas del conflicto armado en Colombia, Bogotá, Colombia: Grupo Editorial Norma.

Pombo, R. (2010). Buscando un equilibrio entre la justicia y la paz: Avances y perspectivas de la Ley 975 de 2005 “Presentación”. Bogotá: Fundación Konrad Adenauer, la Corporación Pensamiento Siglo XXI y Alto Consejero Presidencial para la Reintegración.

Restrepo, J. A. (2006). El Conflicto En Colombia: ¿Quién hizo qué a quién? Un Enfoque Cuantitativo (1988-2003). Bogotá: Norma

Rettberg, A. (2010). Conflicto armado, seguridad y construcción de paz en Colombia. Bogotá: Universidad de Los Andes.

Roy, J. (2005). "La Ley de Justicia y Paz de Colombia: Contexto, perspectivas internacionales, y actitud de la Unión Europea", Miami: University of Miami

Romero, M. (2007). "Nuevas guerras, paramilitares e ilegalidad: una trampa difícil de superar”. Parapolítica. La ruta de la expansión paramilitar y los acuerdos políticos. Bogotá: Corporación Nuevo Arco Iris. 
Sánchez, F. \& Chacón, M. (2006). Conflicto, Estado y descentralización: del progreso social a la disputa armada por el control local, 19742002. Bogotá, Colombia: Norma-IEPRI

Sánchez, G \& Peñaranda, R. (1991). Pasado y presente de la violencia en Colombia. Recuperado de http://www.bdigital.unal.edu.co/35711/.

Uprimmy, R. (2001). El laboratorio colombiano: narcotráfico y administración de justicia en Colombia. Bogotá, Colombia: Uniandes, UN, Siglo del Hombre.
Vargas, A. (2009). Guerra civil en Colombia: el caso de Barrancabermeja. Bogotá, Colombia: CERAC, Pontificia Universidad Javeriana Valencia, G. (2007). "Reconstrucción analítica del proceso de desarme, desmovilización y reinserción de las Autodefensas Unidas de Colombia, 2002-2007”. Perfil de Coyuntura Económica, No 10, julio-dic. de 2007.

Velásquez, E. (2007). Historia del paramilitarismo en Colombia. História (São Paulo), 26(1), 134-153. 